\title{
IZALCO (EL SALVADOR) EN EL CAMINO A «LA MATANZA»DE 1932. UNA APROXIMACIÓN
}

\author{
Izalco (El Salvador) in the way to "La Matanza" \\ in 1932. An approach
}

Antonio Acosta Rodríguez Universidad de Sevilla, España

\begin{abstract}
Resumen: En El Salvador, en 1932, tras un golpe de Estado, el Ejército llevó a cabo una gran represión, conocida como «la matanza», que tuvo en Izalco uno de los más duros escenarios. La oligarquía del país había construido durante décadas una sociedad profundamente desigual. El artículo pone el foco en algunos aspectos de aquella desigualdad y recupera determinadas fuentes no utilizadas hasta hoy en el análisis del proceso.
\end{abstract}

Palabras clave: sociedad, población indígena, ladinos, tierra, café.

Abstract: In El Salvador, in 1932, following a coup d'état, the army carried out a great repression, known as "la matanza" (the massacre), which took place in Izalco, one of the harshest scenes. For decades, the country's oligarchy had built a profoundly unequal society. This article focuses on some aspects of that inequality, recovering certain historical sources that have not been used until now in the analysis of the process.

Keywords: society, native population, ladino, land, coffee.

\section{Introducción}

Este trabajo traza algunos de los rasgos principales del perfil de la localidad salvadoreña de Izalco desde comienzos del siglo xx hasta la crisis económica internacional de 1929, es decir, hasta las vísperas de las graves consecuencias que se derivaron de ella, en el conjunto del país y, especialmente, en esta población. ${ }^{1}$

1. Este artículo se inscribe en el proyecto I+D+i, Ref. PID2019-103879GB-I00, financiado por el Ministerio de Ciencia, Innovación y Universidades. Una versión preliminar fue presentada en la ponencia presentada al simposio «El funcionamiento del poder en el ámbito local. América Latina, si- 
Se trata de caracterizar, en el marco del Estado salvadoreño, el camino de incremento de las desigualdades que vivió Izalco hasta la salvaje represión de trabajadores y sectores populares que sufrió a manos del ejército en enero de 1932. Izalco fue probablemente el lugar castigado de forma más sangrienta. Hubo otras localidades con perfiles parecidos que también sufrieron la represión de «la matanza». Sin embargo, Izalco tenía características singulares que pudieron influir en la existencia de una mayor conciencia política en sectores de su población que en otros lugares; una conciencia de descontento y rechazo a la dominación de la oligarquía. Es posible que esto explicara por qué allí se expandieron con más facilidad las propuestas de resistencia y de cambio al régimen oligárquico salvadoreño. Y, como reacción, que la represión fuese más dura.

Debido a algunas de estas circunstancias mencionadas, Izalco ha atraído la atención de la historiografía desde hace años. ${ }^{2}$ Es mucho lo conocido sobre esta población, por lo que no es fácil añadir nueva información y nuevas reflexiones a lo que ya se conoce. Pero ese es nuestro reto.

\section{El marco estatal}

Para tratar de la vida en un municipio de El Salvador, como era Izalco, es preciso atender inicialmente a algunos aspectos básicos relacionados con el Estado, del cual este, como el resto de los municipios, formaba parte. Sin hacerlo no se pueden comprender cabalmente las políticas locales ni territoriales de un país como El Salvador entre los siglos XIX y XX.

Como prácticamente todos los casos de América Latina, El Salvador nació a la independencia como un país endeudado (Marichal, 1989). Como una parte de las Provincias Unidas del Centro de América, compartió la primera deuda externa y, cuando la Federación se dividió en 1839, heredó la cuota correspondiente de dicha deuda (Smith, 1963). El Estado salvadoreño fue diseñado por una minoría de propietarios terratenientes, militares, intelectuales y religiosos que nunca aprobaron impuestos directos a sus propiedades y a sus rentas. Esta característica se mantuvo a grandes rasgos durante décadas. Por eso, la gestión de la Hacienda pública fue siempre deficitaria y la deuda pública, primero externa y enseguida interna, no hizo más que crecer.

Avanzando en el tiempo y sin entrar en detalles de la historia del incremento de la deuda, en 1908 los gestores del Estado salvadoreño suscribieron otro empréstito por un millón de libras esterlinas, añadido al ya existente, con lo que la deuda pública se situó en casi 35 millones de colones. Desde entonces hasta 1930, tras otro crédito por 32 millones de colones en 1922, la deuda pública

\footnotetext{
glos XIX-XX» organizado por el Taller de Estudios e Investigaciones Andino-Amazónicos de la Universidad de Barcelona y celebrado en Barcelona los días 10 y 11 de diciembre de 2020.

2. La literatura histórica sobre esta coyuntura es muy amplia, pero destacan algunos autores: Anderson (1971), Gould y Lauria-Santiago (2008) y Martínez (2012). Véase una síntesis bibliográfica en: Ching et al. (2007).
} 
ascendió a casi 46 millones de colones. ${ }^{3}$ Dadas las características económicas del país y la calidad de su administración pública no es posible calcular el PIB en aquellos años. Como alternativa para apreciar la gravedad de la deuda, aunque el resultado no equivale a utilizar el PIB, se puede recurrir a las rentas públicas. Así, en 1930, los ingresos fiscales anuales de El Salvador apenas llegaban a 25 millones de colones, de los que más del 70\% estaban hipotecados para pagar la deuda. Por otra parte, El Salvador pasó de exportar 32.600 toneladas de café, casi el 70\% de las exportaciones en 1919 (13,7 millones de dólares en el mercado de Nueva York) a 52.400 toneladas, casi el 93\% del total de las exportaciones en 1928 (24 millones de dólares) (Clarence-Smith y Topik, 2003: 425 y 452). ${ }^{4}$ Para los años que aquí se estudian e incluso antes, el café era la turbina que movía la economía nacional. Aceleró el movimiento del transporte terrestre y portuario para las exportaciones, las empresas de seguros, la actividad financiera, la construcción, el comercio y el abastecimiento al Estado (para las obras que correspondían a él, porque el resto estaba en manos del capital privado).

Sin embargo, la renta del café era distribuida de forma extremadamente desigual. La contribución fiscal era muy regresiva. En 1928 los impuestos directos, que no existieron hasta 1915, suponían menos del $5 \%$ de los ingresos fiscales. Mientras tanto, las importaciones de maquinaria para las instalaciones de la producción y del procesamiento del café que pertenecían al sector más rico del país estaban exentas de impuestos. En 1917, los beneficios anuales de uno de los cuatro socios - el presidente de la República, Carlos Meléndez - de su principal empresa agrícola - tenía otras - eran de 200.000 colones. En cambio, el salario mensual medio de los trabajadores del café a finales de la década de 1920 no llegaba a los 30 colones.

Todo ello significa que el Estado disponía de pocos recursos para atender los gastos de la administración y la inversión en los servicios públicos nacionales. Por su parte, los municipios tenían unas cuentas igualmente deficitarias, condicionadas por los magros ingresos de la mayoría de sus habitantes. Esta grave situación financiera del Estado era crónica, y limitaba negativamente en muchos aspectos la vida de las mayorías sociales y, lógicamente, los problemas sociales y políticos se agudizaron aún más a partir de 1929 con la caída del mercado en Estados Unidos. La crisis que se desató entonces tuvo consecuencias en todo el mundo, pero fue muy intensa en países como El Salvador. Allí la oligarquía había sacrificado la economía del país en aras de la cuasi monoproducción del café, de la que obtenía fantásticas ganancias.

3. Una monografía del autor de este artículo sobre este problema se encuentra en vías de publicación.

4. En estos años el cambio del dólar al colón era de 1:2. 


\section{Territorio, demografía y sociedad}

Izalco se encuentra en el occidente del país. Está a $8 \mathrm{~km}$ de Sonsonate, la capital del Departamento del mismo nombre, a $50 \mathrm{~km}$ de Santa Ana y a otros $50 \mathrm{~km}$ de Ahuachapán. Estas referencias forman una de las zonas de mayor intensidad en el cultivo de café, si no la que más, en el país desde fines del siglo XIX (Lauria-Santiago, 1998). La distancia de Izalco a San Salvador, la capital, es de $80 \mathrm{~km}$ por carretera. En los años que aquí se tratan existía un tranvía de sangre, esto es, de tracción animal, para recorrer los $8 \mathrm{~km}$ hasta Sonsonate. Y, por otra parte, en 1930 había caminos vecinales, se supone que carreteros, que comunicaban a la ciudad con los cantones de su distrito - de los cuales se tratará enseguida- y algunos de ellos entre sí.

Izalco era un municipio caracterizado por su fuerte componente de población indígena. No era el único en este sentido y, como en otros, la fuerza de la cultura originaria se mantuvo en el tiempo en un grado muy alto (Leiva, 2011). Después de la conquista española, varias concentraciones de población nativa pipil-maya en el occidente del territorio, como Tacuscalco, Nahulingo, Izalco, Caluco y otras poblaciones próximas, conformaban una región conocida como Los Izalcos, en plural (Ibídem: 73). Pero el término Izalco, en singular, quedó finalmente restringido para denominar al pueblo al que se dedica este trabajo.

No existe información demográfica seriada sobre El Salvador para los años que aquí se estudian y, consiguientemente, tampoco para Izalco. A mediados de la década de 1920, la población de El Salvador era aproximadamente de 1.360.000 habitantes. ${ }^{5}$ Por otra parte, en 1913, un informe municipal, recogido después por otro de la Gobernación del Departamento, afirmaba que en la localidad vivían 16.117 habitantes, distribuidos entre el centro urbano y 24 cantones. Si la información era fidedigna, ${ }^{6}$ la tasa de natalidad había sido de $18,9 \%$, lo que no era alto, y la de mortalidad había sido de solo 11,3\%.. Próximos a Izalco estaban Juayúa, con 12.000 habitantes, y tres «barrios», y Nahuizalco, con aproximadamente 20.000 habitantes, distribuidos entre el centro urbano y trece cantones. ${ }^{7}$

En 1924 Izalco alcanzaba la cifra de 17.000 habitantes, lo que lo hacía un pueblo de cierta dimensión si se compara, por ejemplo, con la capital del Departamento de Sonsonate, que tenía solo 16.037 (Anuario Estadístico, 1924). Un número desconocido de aquellos habitantes de Izalco seguían viviendo dispersos en los mismos 24 cantones reconocidos individualmente por su nombre. ${ }^{8}$

5. El cálculo se ha realizado a partir de la población «probable» en 1917, según el Anuario Estadístico de aquel año, y la población de 1930, según el censo de dicha fecha.

6. Alcalde de Izalco al gobernador de Sonsonate, en Archivo General de El Salvador (en adelante AGN), Gobernación de Sonsonate (Gob Son), 11/1919, 11 de agosto de 1913. El informe es del 20 de septiembre del mismo año.

7. Alcaldía de Nahuizalco al gobernador del Departamento, en AGN, Gob Son, Nahuizalco, 11/1919, 13 de agosto de 1913. Es muy probable que la población total estuviera sobrevalorada. En 1924 la población de Nahuizalco era de 18.023 habitantes (Anuario Estadístico, 1924).

8. Alcaldía de Izalco al gobernador del Departamento, en AGN, Gob Son, 11/1919, 15 de mayo de 1915. 
Sin embargo, en 1928 el número de cantones se había reducido a 19, quizá porque algunos habían sido absorbidos por otros. ${ }^{9}$

El modelo de Izalco era general en el país. El Salvador tenía un hábitat fuertemente disperso, con un alto número de cantones o valles en cada localidad. En 1930, con menos de un millón y medio de habitantes había más de 2.500 cantones en el país. ${ }^{10}$ Esta fuerte dispersión humana tenía importantes consecuencias desde la perspectiva del encaje de Izalco y del resto de las poblaciones en la administración del Estado. Como es obvio, uno de los principales problemas derivados de este tipo de hábitat era la dificultad para hacer llegar determinadas estructuras y servicios públicos a toda la población distribuida así en el territorio. Entre otros, la expansión y el mantenimiento de la red viaria, la canalización del agua potable y los servicios de salud o de educación para la población en edad escolar se hacían aún más difíciles considerando que la situación financiera de la Hacienda estatal, así como la de las haciendas municipales, era deficitaria. Esta dispersión, heredada en parte del modelo de población campesina precolonial, debilitaba el ejercicio del poder y la gestión, así como la intercomunicación social, no solo nacional, sino también local, como se tratará a continuación.

El espacio del actual El Salvador tuvo una importante población indígena desde la conquista española en términos cuantitativos, muy superior por supuesto al escaso número de los conquistadores castellanos. Los múltiples efectos de la colonización produjeron que a mediados del siglo XIX la relación se hubiera invertido, hasta el punto de que se calculaba que la población indígena del país solo alcanzaba en torno al $25 \%$ del total de habitantes. No parece arriesgado suponer que este porcentaje general podía haber disminuido ligeramente a comienzos del siglo xx. Sin embargo, en localidades como Izalco, es probable que la población indígena superara el 50\%.11 Por comparación, en 1913, en una localidad situada a $5 \mathrm{~km}$ de Izalco y de similar historia, como era Nahuizalco, se calcula que solo el $12,5 \%$ eran no indígenas. ${ }^{12}$ Finalmente, el censo de El Salvador de 1930, registró la sorprendente cifra de solo un $6 \%$ de «indios» y un 93\% de «mestizos» entre los 1.434 .361 habitantes del país. ${ }^{13}$ Cabe pensar que los criterios de identificación de población indígena pudieron haber sido muy restrictivos, y no así los de la población mestiza.

En El Salvador, como en otros territorios de la América colonial, un segmento conocido como los ladinos se fue diferenciando de la población indígena. Los ladinos comenzaban a adquirir algunos rasgos culturales de los castellanos,

9. Alcaldía de Izalco al gobernador del Departamento, en AGN, Gob Son, Izalco, 12/1920-1951, 21 de julio de 1928.

10. Población de la república de El Salvador: censo del $1^{\circ}$ de mayo 1930. El Salvador, Ministerio de Hacienda. Dirección General de Estadística y Censos, 1942.

11. La estimación del 50\% de población indígena para 1915 en Rodríguez-Herrera (2007: 90) carece de base documental.

12. Informe de 20 de septiembre de 1913, en AGN, Gob Son, 11/1919, 20 de septiembre de 1913.

13. Población de la república de El Salvador: censo del $1^{\circ}$ de mayo 1930. El Salvador, Ministerio de Hacienda, Dirección General de Estadística y Censos, 1942. 
pero se mantenían en las comunidades originarias. Este sector fue creciendo de forma paulatina y diferenciándose aún más de las comunidades indígenas. Así, empezaron a formarse comunidades ladinas, también campesinas, de evidente origen colonial. Esta diferencia era fácil de reconocer socialmente y dio lugar a choques entre indígenas y ladinos por diversos motivos, tanto en Izalco como en otros lugares (Giudicelli, 2005). En informes de principios del siglo xx realizados en distintas localidades del Departamento de Sonsonate, la población se clasificaba estadísticamente entre «indios» $\mathrm{y}$ «ladinos». ${ }^{14} \mathrm{Y}$ avanzado el siglo XX, en ciertas zonas del país todavía existía un sector social vinculado a los indígenas, pero considerados ladinos, con ciertos rasgos físicos diferenciados (Clará de Guevara, 1975: 15).

Sin embargo, poco a poco, en el paso del siglo XIX al XX, la voz «ladino» también fue utilizándose al mismo tiempo para otros sectores sociales que no eran de origen indígena. Esto ha hecho que sea un término de difícil definición, y puede complicar a veces el análisis histórico. A comienzos del siglo xx, el concepto podía incluir a blancos criollos, a algunos mestizos e incluso a algunos indígenas altamente aculturados. De ahí que en ciertos contextos se usara el término para referirse a los blancos por contraposición a los indígenas. Por todo ello, es preciso ser cuidadoso al interpretar los procesos sociales. Así, en 1914 el gobernador del Departamento de Sonsonate en un informe al ministro de Gobernación hablaba de la población de Izalco en los siguientes términos:

\begin{abstract}
En su mayoría [son] indígenas, pero hay muchas y muy importantes familias de ladinos, que han logrado dominar a las masas indígenas, pues desde hace muchos años las autoridades locales son integradas por ladinos, a lo cual obedece un florecido progreso. Los indígenas conservan siempre sus costumbres primitivas en todas sus manifestaciones predominando entre ellos el espíritu religioso, congregándose en cofradías, representadas por alcaldes nombrados por ellos, a quien obedecen ciegamente tanto en lo religioso como en lo político, siendo por naturaleza pacíficos y laboriosos; pero cuando se trata de atacar sus creencias y hábitos son temibles y tenaces. Su vicio más arraigado es el alcoholismo [,] que lo ejercitan especialmente en sus festividades, siendo refractarios a la prostitución y demás vicios. ${ }^{15}$
\end{abstract}

Como se puede apreciar, el concepto «ladino» tenía perfiles muy amplios y aquí incluía a familias «muy importantes», es decir, blancas, que habían logrado «dominar a las masas indígenas». Miembros de ellas, y no de la mayoría indígena, eran quienes fungían como autoridades del municipio oficial de Izalco desde hacía «muchos años». También es evidente en el texto la mirada de superioridad del gobernador al hablar del progreso generado por los ladinos, de las «costumbres primitivas» indígenas o del vicio del alcoholismo entre estos. No obstante, como se sabe, el alcoholismo era en realidad un problema nacional extendido por todas las capas y ambientes sociales y no solo entre los indígenas. Por ejemplo, en la propia municipalidad de Izalco, tiempo después de este

14. Véase, por ejemplo, Santo Domingo del Monte, en AGN, Gob Son, 11/1919, 1913.

15. Informe del gobernador del Departamento de Sonsonate al ministro de Gobernación, en AGN, Gob Son, 11/1900-1917, 20 de septiembre de 1914. 
informe, el escribiente Pedro Alejandro Castillo fue retirado de su servicio y se prohibió su contratación por repetidas faltas de ebriedad. ${ }^{16}$ Del texto del gobernador, igualmente merece destacarse la existencia de cofradías indígenas, de las elecciones de sus alcaldes y de su naturaleza «pacífica y laboriosa».

Miembros de aquellas familias «muy importantes» de ladinos (Call, Velado, Pineda, Velásquez, etc.) crearon, en 1915, el Casino Izalqueño. Como en otras localidades del país y del mundo occidental de aquella época donde se fundaron casinos, el de Izalco se trataba de un centro privado que buscaba dar espacio a «distracciones lícitas de una buena sociedad» y que constituía una seña de identidad y de cohesión de la oligarquía frente a otras clases sociales. Para formar parte del Casino era necesario abonar una prima de entrada más cuotas mensuales, con lo que se adquiría el carácter de "socio accionista». Además, el Casino tenía una servidumbre al servicio de los socios. ${ }^{17}$ Probablemente, las diferencias sociales se manifestaban aquí, al igual que en otros espacios de la realidad.

Por contraposición a estos ladinos, había muchos otros en la esquina opuesta de la sociedad. Era, por ejemplo, el caso de un Jerónimo Torres, «hombre ladino", de 65 años, que falleció de indigestión sin asistencia médica, en Armenia, localidad próxima a Izalco, en enero de 1924. Su viuda, hija natural y mucho más joven que él, quiso casarse de nuevo y solicitó a la justicia que se evaluaran los bienes del difunto. Para ello, el juzgado en el que se llevaba el caso nombró a unos peritos, que todo lo que tuvieron que tasar fue un par de cántaros de cinc «en regular estado» y una piedra de moler. El valor que le dieron a todos los bienes fue de solo 6 colones. ${ }^{18}$ Este caso, como otros muchos, evidencia que la referencia al término «ladino» en la documentación puede significar realidades muy distintas y alerta sobre la precaución que debe tenerse con este concepto cuando se trata de hacer un análisis social.

\section{Organización institucional y administrativa}

A comienzos del siglo xx, el casco urbano de Izalco estaba dividido en ocho barrios: Dolores, Asunción, San Sebastián, San Juan, Santa Cruz, Santa Lucía, Santa Teresa y La Otra Banda. Salvo uno, todos eran nombres asociados a la religión católica, reflejo de la conquista y la colonización españolas. Los más importantes entonces, y hasta hoy, eran Dolores y Asunción, que contaban con dos cabildos, uno en el «Pueblo de Arriba» y otro en el "Pueblo de Abajo". Estas expresiones podían tener relación con las diferencias de altitud que existen en el caserío del pueblo, pero también con las relaciones entre blancos e indígenas. Y es que Dolores estuvo constituido, desde la colonia, mayoritariamente por población blanca, mientras que Asunción, casi exclusivamente por población indígena. Ambos distritos se unieron administrativamente

16. Sesión municipal en Archivo Municipal de Izalco (en adelante, AMI), 5 de septiembre de 1927.

17. Estatutos del Casino Izalqueño en el Diario Oficial (en adelante DO), 26 de julio de 1915.

18. Inventario de bienes de Jerónimo Torres, en AGN, Fondo Judicial (FJ), Son-Civiles, Armenia, 1928/99-1, 1924. 
en la década de 1860, pero siguieron separados por su composición étnica y cultural. ${ }^{19}$

En cuanto a la existencia de dos cabildos y, por consiguiente, de dos alcaldías, hay que decir que suponía una relevante originalidad no conocida en otras localidades vecinas. Por una parte, estaba la Alcaldía Municipal, de origen colonial e insertada en el aparato institucional del Estado. Y por otra parte existía la conocida en términos castellanos como Alcaldía del Común, que no era reconocida en la estructura estatal. ${ }^{20}$ En efecto, desde antes de la colonia, los indígenas tenían una institución representativa desde la que se gestionaban diversos aspectos de su vida económica, social y política. Hasta el siglo XIX, cuando el pueblo indígena aún tenía tierras comunales, esta institución era la instancia que atendía a las cuestiones relacionadas con el agua y la agricultura, y donde se resolvían los problemas del diario vivir. Los colonizadores extendieron a esta institución los términos del español, heredados del árabe, alcaldía y alcalde. Por lo tanto, el alcalde del Común o de los indígenas se elegía por la comunidad y era, junto con los mayordomos de las cofradías, una de las autoridades de más predicamento entre los naturales. Esta alcaldía se mantuvo durante la historia republicana y, pese a las consecuencias de «la matanza» y la represión cultural a la que fue sometida la población indígena durante muchos años después, la Alcaldía del Común siguió funcionando. De hecho, se conservan actas de sus reuniones hasta 1972 (Rodríguez-Herrera, 2007).

La existencia de esta alcaldía constituía una singularidad de Izalco que demuestra la fuerza cultural de la población indígena local. Era un rasgo que, junto con otros, ayuda a explicar por qué, cuando se produjeron los sucesos de enero de 1932, la violencia de la presión oligárquica y militar se ensañó de forma especialmente cruel con aquel sector de la población.

La diversidad étnica ha jugado un papel relevante en la historia de El Salvador. Los intereses, coyunturales o estructurales según el momento, de las comunidades indígenas y ladinas han hecho que en distintas ocasiones hayan protagonizado movimientos sociales de diferente carácter (Lauria-Santiago, 1995; López Bernal, 2000, 2008; Rivas, 2002). No obstante, en alguna ocasión y, en concreto, en Izalco, la participación de algunas comunidades en movilizaciones de proyección más allá de lo local quizá no ha sido bien interpretada.

Un conflicto que involucró a indígenas y ladinos ocurrió en Izalco en noviembre de 1898. Eran los días en que tenía lugar el golpe de Estado con el que el general Tomás Regalado (1898-1902) derrocó de la presidencia de la República a su antiguo amigo Rafael Antonio Gutiérrez (1894-1898). El incidente se concretó en un enfrentamiento con asalto a instalaciones municipales y varios muertos, y tuvo trascendencia nacional. ${ }^{21}$ Los intentos de explicación de este acontecimiento han tenido una fuerte carga especulativa, y para ello se han ma-

19. Informe de poblaciones y cantones del Departamento de Sonsonate, en AGN, Gob Son, 11/1919, 1915.

20. El autor de este artículo desconoce la denominación de la institución en náhuatl.

21. Amnistía a individuos que tomaron parte en la rebelión del 14 de noviembre de 1898 en Izalco en DO, 16 de mayo de 1900. 
nejado una diversidad de factores sociales y políticos, algunos relacionados con el proceso de reparto de tierras de comunidad que había tenido lugar en Izalco años antes (Lauria-Santiago, 1999). Sin duda, había muchas variables en la política nacional en torno a la decisión de derribar el gobierno por parte de Regalado que pueden tenerse en cuenta para que se produjeran problemas como el de Izalco. Pero es imprescindible considerar dos factores que movieron al golpe de Estado, para el que Regalado necesitaba apoyos. Uno era la catastrófica política fiscal y financiera que había llevado a cabo Rafael Antonio Gutiérrez, la cual había elevado la deuda pública a 35 millones de colones y había causado la quiebra de muchos empresarios. El otro era la firma de Gutiérrez para incluir a El Salvador en la creación de la República Mayor de Centroamérica, que pretendía ser una reunificación parcial de América Central. A raíz de ello, se estaba planeando establecer en Nicaragua el Estado Mayor de los ejércitos centroamericanos. Regalado, un fuerte cafetalero con algunas propiedades en Izalco y, además, con un carácter de vedete política, era radicalmente opuesto a la creación de la República Mayor y a la instalación del poder militar fuera de El Salvador. Sin estas circunstancias no se puede explicar cabalmente lo sucedido en Izalco. Y la prueba de que esto era así es que Regalado rompió el compromiso con la República Mayor inmediatamente después de asumir la presidencia tras el golpe.

Además, existe una versión del incidente de noviembre de 1898 facilitada por el gobernador de Sonsonate unos doce años después de lo sucedido que contribuye a la explicación del problema. Merece la pena reproducir el texto de este informe, no solo por la visión que da de lo que ocurrió, sino también porque refleja el punto de vista del informante sobre la sociedad y la cultura indígenas:

\begin{abstract}
En sus anales históricos trágicos y horrendos episodios emanados de las evoluciones políticas en que algunos caudillos regionales[,] explotando la crasa ignorancia de los indígenas, los precipitan a la vorágine de la criminalidad más espantosa con tonos de salvajismo, tal como lo ocurrido el 14 de noviembre de 1898 en la cuesta del "Quilite», del cantón de Cuntan, a dos leguas de distancia de la ciudad en que una turba de indios de opuesto bando salieron a atajar un regular número de ladinos que se dirigían a dicha ciudad [¿lzalco?] para San Salvador a incorporarse a las fuerzas del general Regalado, a raíz de los acontecimientos políticos que ocurrieron en aquel año, y que dieron margen a la exaltación al poder de dicho caudillo, de cuyo encuentro resultaron varios muertos y heridos, lo que demuestra las funestas consecuencias que ocasiona el espíritu de partido inculcado en las masas ignaras que, sin el menor miramiento, se lanzan al crimen solo por inducción sin perseguir ningún ideal propio que pudiera reportarles algún beneficio. ${ }^{22}$
\end{abstract}

Si se acepta esta versión, el enfrentamiento se habría producido en el contexto del golpe de Estado en noviembre de 1898, y tanto indígenas como ladinos $-y$ aquí tropezamos con la duda: ¿de qué ladinos se estaba hablando?habrían sido instigados por minorías blancas partidarias del general golpista Tomás Regalado y del general destituido, Rafael Antonio Gutiérrez. Según el go-

22. Informe del gobernador del Departamento de Sonsonate al ministro de Gobernación, en AGN, Gob Son, 11/1900-1917, 20 de septiembre de 1913. 
bernador que facilita esta versión, los indígenas habrían sido inducidos al enfrentamiento por elementos ladinos, sin que en realidad ellos tuvieran interés propio en el caso que pudiera reportarles ningún beneficio.

Si ocurrió así, se habría tratado de los efectos de la lucha por el poder central del Estado, manejados por minorías del poder local con consecuencias terribles para la mayoría indígena y probablemente para un sector de los ladinos. El acontecimiento tuvo mucha repercusión en San Salvador. Hubo prisioneros - algunos de ellos con apellidos indígenas - , juicios, algunos condenados a muerte y también indultos. ${ }^{23}$ En todo caso, fue otra singularidad de Izalco y no parece que se produjera un acontecimiento similar en otro pueblo o ciudad.

\section{Las bases económicas: la tierra}

Con los comienzos de la expansión del cultivo del café a mediados del siglo XIX, finqueros y comerciantes, sobre todo del occidente del país, comenzaron a expandir sus propiedades, presionando a las comunidades indígenas en relación con sus tierras, si bien llegaron a hacer negocios en algunos casos (Acosta, 2013: 120 y ss.). En Izalco, en la década de 1920, las principales producciones eran caña de azúcar (15.000 quintales/año), maíz (300 fanegas), frijoles (200 fanegas), ${ }^{24}$ pastos, bálsamo, café (2.000 quintales/año), arroz y frutas. Además, se criaba ganadería vacuna y caballar. Lo que en terminología de la época en el país se llamaban «industrias», en Izalco se dedicaban a la fabricación de petates, petacas, canastos y objetos de alfarería y almidón de yuca. ${ }^{25}$ El distrito era atravesado por tres ríos: el Atecosol, el Agua Caliente y el Sunsula, además de otros cursos de agua menores (Anuario Estadístico, 1924).

Como es de sobra conocido, en 1881 y 1882 en el marco de la expansión económica y con el café desplazando al añil como primer producto de exportación en términos de valor, la oligarquía salvadoreña que controlaba la administración central del Estado llevó a cabo la extinción de las tierras de las comunidades indígenas, así como de los ejidos municipales. Esto, que algunos historiadores han considerado tradicionalmente una de las «reformas liberales», formaba parte de la acumulación originaria en manos de la oligarquía (Menjívar, 1980). En el caso de las tierras comunales, en contra de lo que alguna vez se ha afirmado, no se produjo una expropiación de la tierra de comunidades (Alvarenga, 2012: 13). El proceso no fue como el de las compañías deslindadoras en México, cuando se expropiaron tierras donde no existían títulos de propiedad. En El Salvador, en el caso de las comunidades de indígenas y de ladinos, lo que se hizo fue repartir las tierras entre los comuneros,

23. DO, 16 de mayo de 1900 . Véase la nota 21.

24. En la actualidad se desconoce la equivalencia del peso de la fanega de hace un siglo en El Salvador. Podía oscilar entre las 70 y las 90 libras, es decir, aproximadamente unos 30 o 40 kilos.

25. El Salvador tenía instalaciones de actividades agroindustriales, como beneficios de café o ingenios de azúcar, pero el término «industria» era utilizado genéricamente para elaboraciones artesanales, como era este caso. 
concediéndoles títulos de propiedad; es decir, primero se privatizó la tierra. Los comuneros, al pasar a ser pequeños propietarios, quedaron expuestos a las fuerzas del mercado en posición extremadamente débil. Y cuando se vieron cada vez más necesitados de recursos monetarios por la presión fiscal del Estado y de la economía mercantil, en muchos casos terminaron malvendiendo sus tierras.

El distrito de Izalco era de un gran potencial agrario y se encontraba en la zona de expansión del café, por lo que se vio envuelto en este proceso de las antiguas tierras comunales. La privatización de la tierra no se llevó a cabo con rapidez por toda la geografía del país. En el caso de Izalco, la Administración central del Estado no fue diligente. El proceso dio lugar a una diversidad de importantes incidentes en la medición, el reparto de tierras y la concesión de títulos durante parte de las décadas de 1880 y de 1890 (Lauria-Santiago, 1999). Todavía en 1895, varios miembros de la comunidad de Asunción de Izalco, cuyas tierras habían sido repartidas, solicitaron al Gobierno que declarase válidos los títulos de las tierras que habían recibido en cumplimiento de la ley de abril de 1881, porque sufrían ciertas informalidades derivadas del retraso con que habían actuado las autoridades responsables de implementar dicha ley. El gobierno del general Rafael Antonio Gutiérrez, por medio del ministro de Gobernación, Prudencio Alfaro, respondió en junio de dicho año, validando los títulos de que disponían, considerando que no era «justo privar a aquellos ciudadanos del derecho que tenían... tanto más, cuanto que constituyen parte de la clase más desvalida del pueblo». ${ }^{26}$ En realidad, la frase de Gutiérrez era apropiada para un miembro de la oligarquía nacional, pero más ajustado a la realidad habría sido referirse a la clase más despojada del pueblo.

Por otra parte, unos años después, en abril de 1901, varios vecinos de los valles o cantones de El Chorro, Matazano, Teshacatito, Cuyagualo y otros que componían antiguamente la comunidad de Dolores de Izalco solicitaron que se volvieran a medir sus propiedades. El origen de esta petición era que los antiguos títulos de los terrenos comunales, que habían sido otorgados por decisión real en 1582, se encontraban «muy oscuros». ${ }^{27}$ Esta circunstancia era muy significativa porque reflejaba el fuerte carácter institucional y cultural que seguía teniendo esta antigua comunidad indígena que conservaba y valoraba los títulos de tierra coloniales otorgados por Felipe II, aunque se encontrasen ya ilegibles. ${ }^{28}$ De nuevo, este caso era singular y no se conoce que se produjera una situación similar en ningún otro lugar de El Salvador.

El espacio rural de los cantones, de población mayoritariamente indígena, era, en una medida que no se puede precisar, diferenciado de la zona ocupada por las fincas de propiedad de población blanca, que a veces era considerada

26. DO, 10 de junio de 1895 .

27. Gobernador de Sonsonate al ministro de Gobernación, en AGN, Ministerio de Gobernación (en adelante, MGob), Sonsonate, 1901/23, 15 de abril de 1901.

28. No deja de ser paradójico que al comienzo del siglo xx los indígenas esgrimieran como fundamento de su derecho a la tierra títulos otorgados por el rey de los conquistadores que los habían expoliado. 
ladina. Así, en octubre de 1906 se produjo un temporal que debió de ser de gran envergadura, porque originó fuertes daños en viviendas y producciones, al menos en el Departamento de Sonsonate. El alcalde de Izalco, como los de otras localidades, informó al gobernador del Departamento de las graves consecuencias sufridas por propiedades y bienes de 33 vecinos de apellidos españoles, algunos muy conocidos, como Barrientos, Velásquez, Velis y Campos. Al margen de ello, el alcalde añadía que, respecto a lo ocurrido en los cantones, informaría tan pronto como recibiese la información que había requerido a los comisionados respectivos. ${ }^{29}$ Los comisionados eran la figura delegada de la administración municipal en los cantones.

En el transcurso de los años posteriores a la extinción de las tierras de comunidad, buena parte de la población campesina fue perdiendo sus propiedades por ventas a particulares, como se indicó, o porque estas fueron ocupadas violentamente por finqueros poderosos. ${ }^{30}$ Un ejemplo de venta de tierra fue el de un tal Higinio Núñez, miembro de la comunidad conocida popularmente como «la plebe del volcán», en referencia al volcán Santa Ana, en el entorno de Izalco. En 1894, es decir, trece años después de la extinción de las tierras de comunidad por el Estado, Núñez era todavía propietario de 4 manzanas y media de tierra, equivalentes a algo más de 3 hectáreas. En ellas tenía 3.500 árboles de café, tres tareas ${ }^{31}$ de caña y algo de frijol y maíz. A la muerte de su mujer, y por intervención de un hijo suyo, los bienes fueron inventariados y se valoró la propiedad en 4.000 colones. Sin embargo, ese mismo año, Núñez la vendió a Jaime Batlle, conocido cafetalero de Santa Ana, por 2.000 colones. ${ }^{32}$ Es un claro ejemplo de cómo al menos parte de las antiguas tierras comunales fue pasando, por necesidad de liquidez de sus propietarios, a manos de cafetaleros, en condiciones muy favorables para estos últimos.

El mercado de tierra fue acelerándose en esta zona del occidente y centrosur del país como consecuencia del café. En Izalco, poco a poco, propietarios blancos habían ido penetrando en el espacio rural de los cantones y comerciaban con terrenos de mediana o gran superficie. Por ejemplo, en el valle -término sinónimo de «cantón»- Talcomunca, en 1925 una tal Anacleta Castro, viuda de Arévalo, vendió a Dionisio Aquino, agricultor de Izalco y con residencia en el mismo valle, un terreno de 40 manzanas (28 hectáreas) que estaba cultivado con zacate y disponía de ganado vacuno y caballar, marca de herrar, casa de teja, etc., por 1.000 colones, que era un precio muy bajo. La finca lindaba con otras de propietarios de apellidos españoles, como Cuadra, Arce, Araujo, Velado, Trigueros y otros. ${ }^{33}$ En distintos puntos, las tierras de los campesinos o pe-

29. AGN, Gob Son, 11.

30. Véase la queja de la comunidad de ladinos de San Juan de Masajapa (Departamento de La Libertad) por los abusos del importante cafetalero Dr. Emilio Álvarez y sus hermanos (AGN, MGob, 1893/12).

31. Unidad de superficie desigual según las características del terreno. Se puede considerar en torno a $1.000 \mathrm{~m}^{2}$.

32. AGN, FJ, Santa Ana (en adelante, SA)-Civiles, 1895/66-8.

33. AGN, FJ, Son-Civiles, 1928-99. 
queños agricultores de las antiguas comunidades colindaban con grandes haciendas cuyos propietarios solo cultivaban una pequeña parte de café. Era el caso de un comerciante italiano de apellido Martino, propietario de la hacienda Los Naranjos, en Sonsonate, de 48 caballerías o más de 2.110 hectáreas, que lindaban con tierras de Izalco. Sus bienes, que incluían una cantidad apreciable de ganado, estaban valorados en 72.000 colones. $^{34}$

Naturalmente, también se producían transacciones entre la misma población indígena de superficies menores que la de la venta anterior. Los libros de los Juzgados de Paz de Izalco son una fuente excelente para una diversidad de asuntos. De dicho fondo procede el caso de Gregorio Tepas, de 75 años, «pequeño agricultor» del cantón Cuntán, de Izalco, que en enero de 1924 era propietario de un terreno de 10 manzanas cultivado en parte de café, y el resto inculto. La parcela lindaba con terrenos de otros propietarios de apellidos indígenas, como Sixco, Shaste o Pilía. La tierra la tenía por concesión que le hizo el alcalde municipal de la ciudad en 1920, y vendió a la señora Jesús González, viuda de Rosales, solo 2 manzanas y 2 tareas (145 áreas) por 200 colones. Este tipo de ventas de una parte de las propiedades probablemente respondía a la necesidad de disponer de liquidez sin llegar al extremo de tener que deshacerse de toda la tierra. ${ }^{35}$

Otro fondo documental muy rico en información es el de la notaría municipal de Izalco, cuyo estudio permitirá en el futuro un conocimiento detallado de este asunto y de otros de la vida local. En esta misma línea y con terrenos aún menores, en enero de 1922, Ana Castillo, de 23 años, inscribió en la notaría municipal de Izalco la escritura de venta de un terreno rústico, fértil e inculto a Jesús Teshe, de 48 años, viudo y «medio agricultor». La propiedad estaba en Tunalmiles, otro de los cantones de la ciudad. Castillo vendía «37 tareas, o sea 103 áreas, 60 centiáreas, con mojones de madera» (1 hectárea $+300 \mathrm{~m}^{2}=10.300 \mathrm{~m}^{2}=$ casi 2 manzanas), que era parte de otro terreno mayor que ella había comprado en 1919. La venta fue por 127 colones. Teshe quedaba obligado a la evicción y saneamiento en caso necesario. ${ }^{36}$

Otro ejemplo de transacciones de pequeñas cantidades de tierra es de junio de 1926. Entonces un tal Fabián Pilía, de Izalco, jornalero, registraba en la notaría municipal la venta de una tierra a Francisco Méndez, del mismo domicilio, «agricultor en pequeño». El terreno, con 52 áreas y 50 centiáreas, estaba inculto y lo vendió por 160 colones. Fabián lo había comprado a la señora Josefa Pilía, pero había extraviado la escritura. ${ }^{37}$ El extravío de la escritura no tendría que llamar la atención, pero contrasta con el caso de la comunidad de Dolores, que había conservado las suyas desde 1582.

Las operaciones de menor cuantía, como las citadas, son muy numerosas y se registraban en la notaría municipal o, eventualmente, en expedientes de conflictos planteados ante alguno de los dos juzgados de paz que existían en Izal-

34. AGN, FJ-SA-Civiles, 1896/67-3.

35. Juzgado Segundo de Paz de Izalco, 21 de enero de 1928.

36. Protocolos notariales de la Municipalidad de Izalco en AMI, Libro 1922.

37. Protocolos notariales de la Municipalidad de Izalco en AMI, Libro 1926-I. 
co. Por el contrario, las compraventas de mayor envergadura, como la de Anacleta Castro, se sustanciaban ante notarios privados, lo cual marcaba un rasgo de diferencia social en el terreno de las operaciones mercantiles.

La mercantilización de la economía se aceleraba y lógicamente afectaba de lleno al café. Hoy se conoce bien que comerciantes y grandes productores recurrían a la compra a futuro de café de pequeños productores. Estos, presionados por el mercado y por los impuestos municipales, necesitaban liquidez y recurrían a vender el poco café que podían producir a precios bajos y avalando la venta generalmente con sus propiedades. Muchos de ellos se veían obligados, además, a emplearse como jornaleros en otras fincas. Esto sucedía, por supuesto, en Izalco y baste como muestra un ejemplo tomado de uno de los juzgados de paz de Izalco: Juan Munto se declaraba jornalero y residente en el cantón de Cuntan, de Izalco; sin embargo, además de trabajar por cuenta ajena, en abril de 1919 había vendido 6 quintales de café en oro (o sea, 12 quintales en cereza bien seca) por 77 colones (esto es, a 12,80 colones el quintal) a Vicente Viscarra, que se definía como negociante. ${ }^{38}$ El precio del café en el mercado local después de la cosecha de aquel año estuvo en torno a los 20 colones/quintal de café en oro, por lo que el margen comercial en la compra realizada por Viscarra era del 36\%; un gran negocio. Sin embargo, Munto no entregó el café que había vendido a futuro en la fecha establecida, por lo que Viscarra emprendió acciones legales contra Munto en el Juzgado Segundo de Paz de Izalco. Lo acusaba de estafa y llegó a afirmar, sorprendentemente, que Munto no tenía ni había tenido nunca café para vender. Si esto era cierto, ¿cuándo lo supo Viscarra?, ¿cómo no comprobó antes si Munto podía entregar el café? El caso sirve como ejemplo de la efervescencia que se vivía en el mercado del café, pero Munto había desaparecido. Viscarra insistió ante el Juzgado para que se localizara al deudor, pero en 1928 este seguía sin aparecer y el caso se cerró. ${ }^{39}$

Este final con la desaparición de Munto no era habitual. Normalmente los deudores se sometían a la decisión de la justicia por el incumplimiento de su contrato. Pero el mecanismo de compra de café a futuro con márgenes de ganancia por parte del comprador, que podía llegar al $100 \%$ con respecto al precio de mercado del café, era muy común. Era practicado por comerciantes intermediarios, pero también por grandes productores que ampliaban de esta manera, es decir, a bajo coste, el volumen total de café que exportaban. ${ }^{40}$

Por otra parte, al margen del café, las deudas entre la gente humilde eran muy frecuentes y, en caso de conflictos, se solía llegar a arreglos entre las par-

38. En estos años, en El Salvador se utilizaba la libra de 465 gramos y el quintal era de $46,5 \mathrm{~kg}$. 39. Pleito contra Juan Munto por estafa de 6 quintales de café en AGN, FJ, Gob Son-Civiles, 1928/99.

40. Por ejemplo, sobre Ángel Guirola, en DO, 11 de enero de 1894. Sobre James Hill, su pleito contra Juana Peñate (AGN, FJ, SA-Civiles, Santa Ana, 1911/82, 22 de agosto de 1911). 
tes ante el juez de paz. ${ }^{41}$ La capacidad adquisitiva de buena parte de la población era escasa y no solo en Izalco. Por ejemplo, en enero de 1928 un hombre aparentemente muy pobre debía 10 colones de compras al fiado. Para cumplir con la deuda se comprometió a ahorrarlos de la paga que recibiría en el trabajo al que se iba a incorporar, que, dado que estaban en enero, probablemente era la corta del café en alguna finca. En otro trabajo era difícil poder ahorrar $10 \mathrm{co-}$ lones en veinte días, que fue a lo que él se comprometió. En el acta correspondiente el juez redactó la descripción del hombre y su compromiso en los siguientes términos:

45 años, trigueño, bronceado, pelo negro liso, barba y bigote ralo, una cicatriz al costado del ojo derecho, algo sapo - ancho de espalda-, descalzo. Se va a trabajar al campo de Arístides Castillo. Y aquí vive por San Juan. Traerá 10 colones a este Juzgado el miércoles 15 de febrero entrante. Izalco, 25 de enero de $1928 .{ }^{42}$

Los casos que se presentaban ante los Juzgados de Paz eran muy variados. Uno, de contenido poco frecuente, fue la denuncia presentada en octubre de 1928 contra Francisco Zaña, de 40 años, soltero, jornalero, por Bernarda Herrera, con quien tenía una criatura. Herrera lo requería para que le ayudara en el cuidado del niño con lo que él pudiera. Zaña declaró que, aunque no tenía ninguna relación amistosa con Herrera, la ayudaría con 20 reales (que equivalían a 2,50 colones) mensuales, los cuales le llevaría al Juzgado para que ella los recogiera allí. El juez estableció que, si no cumplía su compromiso, le impondría una multa de 5 colones cada vez. ${ }^{43}$

Como se puede comprobar, abundaban los casos derivados de la precariedad económica, lo que, además de las dificultades sociales y desde otro punto de vista, remite a las débiles finanzas municipales. Por otro lado, las bajas rentas de gran parte de la población daban lugar al negocio del crédito, que generaba un mercado con múltiples agentes en el país, desde prestamistas particulares hasta instituciones de diverso nivel, desde bancos hasta casas de préstamo. En Izalco había una de estas últimas, como consta en la tabla 1. En la tabla se registran diversas empresas y actividades existentes en la ciudad, entre las que conviene destacar las propiedades del gran empresario Eugenio Araujo y de la viuda del expresidente Tomás Regalado.

41. Véase el alto número de casos en el Juzgado Primero de Paz de Izalco, en AGN, FJ, SonCiviles, 1927/98, 1927.

42. Juzgado Primero de Paz de Izalco, 13 de enero de 1928.

43. Juzgado Primero de Paz de Izalco, 24 de octubre de 1928. 
Tabla 1. Empresas e instituciones comerciales. Izalco, 1924.

\begin{tabular}{|c|c|c|c|c|c|}
\hline Baños públicos & 3 & Casas de préstamo & 1 & Ingenios de azúcar $^{\text {b }}$ & 2 \\
\hline Barberías & 5 & Comerciantes tejidos & 5 & Platerías & 1 \\
\hline $\begin{array}{c}\text { Beneficios de café } \\
\text { (a vapor) }{ }^{a}\end{array}$ & 2 & $\begin{array}{c}\text { Congregaciones } \\
\text { religiosas }\end{array}$ & 3 & Panaderías & 2 \\
\hline Biblioteca & 1 & Fábricas jabón y velas & 6 & $\begin{array}{c}\text { Pulperías / tiendas } \\
\text { de comestibles }\end{array}$ & 8 \\
\hline Boticas & 2 & Fábrica de ladrillos & 1 & Sociedades de obreros & 1 \\
\hline Carnicerías & 3 & Ganaderos & 5 & Talabarterías & 1 \\
\hline Carpinterías & 3 & Herrerías & 5 & Zapaterías & 8 \\
\hline Hoteles & 1 & Hojalaterías & 2 & &
\end{tabular}

a. Propiedades de Eugenio Araujo y de Concepción, viuda de Tomás Regalado.

b. Propiedades de Eugenio Araujo y de Concepción, viuda de Tomás Regalado.

Fuente: Anuario Estadístico, 1924: 510-511.

\section{La mano de obra}

En el marco de los cambios económicos que se estaban produciendo, cada vez más hombres y mujeres habían ido alimentando el mercado laboral que crecía con la expansión del café y con otras actividades derivadas también del crecimiento demográfico. La pérdida de la tierra era la desnaturalización del campesino. Se trataba de un proceso que había empezado con la colonia española, pero ahora vivía otro de los momentos más duros. Ello forzaba a la mercantilización de su fuerza de trabajo y del factor natural de su subsistencia, que era la tierra. Quienes podían, conservaban una pequeña parcela de tierra que les proporcionaba algo de alimento o incluso, como se ha visto, alguna producción para vender. Esto lo combinaban con su trabajo por un jornal, en lo que ha sido calificado acertadamente de semiproletarización (Menjívar, 1979: 33). Como se ha mencionado y se comprobará más adelante, el aumento de los impuestos municipales con la expansión urbana acentuaba su dependencia del mercado de trabajo en actividades asociadas al crecimiento de la economía nacional, como obras públicas, por ejemplo.

La evolución de los jornales en El Salvador fue muy lenta durante décadas. A finales del siglo XIX, un trabajador rural cobraba normalmente entre 3 y 5 reales al día (expresados en centavos, entre 37,5 y 62,5$),{ }^{44}$ pero treinta años más tarde, en 1929, los jornales de 50 centavos diarios no habían desaparecido. Todavía había lugares en los que se seguía pagando esta cantidad, al menos a los peones de obras en carreteras, lo que suponía un salario mensual de 12 colo-

44. Planillas de la finca Villanueva en AGN, FJ, San Salvador-Civiles, 1907 78/15; Cuaderno de planillas de finca Santa Isabel (Santa Ana), en exposición en Sala de Investigación del AGN, 2008. 
nes que podrían sumar al sustento que pudieran conseguir quienes hubieran conservado algo de tierra.

Dicho jornal se pagaba, por ejemplo, en Tacuba (Ahuachapán), a unos 50 km de Izalco. Y, cuando algunos trabajadores protestaron por el nivel de su salario, el alcalde y, sobre todo, el gobernador del Departamento se vieron obligados a explicar la existencia de jornales de 50 centavos. El primero dijo que era «imposible tratar con los indígenas» y que llegaban tarde a su jornada laboral de ocho de la mañana a cuatro de la tarde. Por su parte, el segundo adujo que las protestas eran incitadas por «sindicalistas que se habían constituido en directores de los campesinos». Afirmó que no era cierto que se hubiera encarcelado a ningún trabajador, ya que había hecho averiguaciones sobre el caso, lo que evidencia que la posibilidad existía. Además, aseguró que nadie había sido obligado a trabajar porque en Tacuba había «abundantes brazos»; y que si en otras localidades del mismo Departamento se pagaban salarios de 75 centavos y hasta de 1 peso era porque en aquellos lugares los individuos eran «verdaderos trabajadores». ${ }^{45}$ Son significativas las reflexiones sobre los indígenas y las referidas a «sindicalistas» y «directores de campesinos», pero, en cualquier caso, el jornal era humillante.

Si fuese cierta, la falta de puntualidad de los trabajadores podría tratarse de una forma de protesta por el bajo jornal. Y, además, el tono en el que usa el término «sindicalista» parece reflejar el rechazo, al menos de los políticos, hacia el papel de los representantes de la clase obrera que trataban de organizar sus reivindicaciones laborales (Menjívar, 1979), algo a lo que la oligarquía se negaba de forma muy clara.

Esta actitud resistente a las reivindicaciones obreras se mantuvo durante los gobiernos de Alfonso Quiñónez (1923-1926) y de Pío Romero (1927-1930), el supuesto padre de la democracia, según varios autores. En alguna ocasión se ha transmitido la idea de la existencia de un cierto apoyo de gobiernos de la oligarquía a las organizaciones mutualistas y obreras a comienzos del siglo xx, pero hay datos que dificultan sostener esa tesis.

Durante los años de gobierno de estos dos presidentes se retrasó sin excusa legal, por motivaciones exclusivamente ideológicas, la legalización de la Federación Regional de Trabajadores de El Salvador (FRTES). Con ello, alguna de las medidas adoptadas por Pío Romero Bosque, supuestamente favorecedoras de una apertura hacia la clase obrera, carecieron de vigencia. ${ }^{46}$ Estas eran las actitudes radicales y reaccionarias de la oligarquía. En contra de lo que cierta historiografía ha reiterado hasta la saciedad de que los trabajadores se radicalizaron, se puede comprobar que quienes se mantuvieron en posiciones radicales durante décadas fueron los cafetaleros y la oligarquía en el poder. ${ }^{47}$ Este era el camino a «la matanza».

45. AGN, Gob Son, 12/1920-1951.

46. Declaración firmada por el ministro de Gobernación, San Salvador, 7 de noviembre de 1927; Constitución de la Federación Regional de Trabajadores de El Salvador (FRTES), 23 de noviembre de 1924; y FRTES a ministro de Gobernación en AGN, Gob, San Salvador, 1927/49-5, 22 de noviembre de 1928.

47. Alvarenga (2012: 240-241) llega a utilizar hasta seis veces por página las expresiones «radicales» y «radicalización» para referirse a sectores subalternos y sus tendencias en aquellos años. 
Regresando al caso de Tacuba, la cuestión es que, pese a los ribetes de desprecio por los indígenas y de la acusación contra los "sindicalistas", el gobernador decidió elevar el jornal de los peones de Tacuba a 75 centavos diarios, que era un jornal que ya se pagaba a los mozos o peones en obras públicas en 1911 e incluso antes. Esto permitía que estos trabajadores alcanzaran unos fabulosos (entiéndase el sarcasmo) 18 colones mensuales. ${ }^{48}$ Pero no eran solo los indígenas los que experimentaban fuertes desigualdades. También existían fortísimas diferencias sociales en los espacios sociales mestizo y blanco.

\section{El cuadro municipal en el contexto económico}

La gestión municipal de Izalco era mutatis mutandis un trasunto de la que desarrollaba la Hacienda nacional. La institución municipal era, por lo general y tradicionalmente, deficitaria en El Salvador. Las tarifas de arbitrios y tasas municipales no eran aprobadas por los propios municipios, sino por la Asamblea Nacional. Y, en vista de los constantes problemas económicos de las instituciones locales, aquellas tarifas eran renovadas de forma periódica. En otro sentido, pero en relación con esto mismo, diferentes gobiernos aprobaron también nuevas y sucesivas leyes municipales con el objetivo de conseguir que los municipios, apurados por sus necesidades financieras, cesaran de solicitar continuamente subvenciones extraordinarias a la Asamblea para poder llevar a cabo proyectos de obras y servicios (Acosta y Flores, 2011). Sin embargo, en términos generales, los problemas municipales no se solucionaron.

Una de las claves de carácter crónico de esta situación era la regresividad de las tasas e impuestos municipales, una característica que también tenían los presupuestos del Estado. El segundo aspecto estratégico para explicar el cuadro hacendístico municipal era, como ya se ha adelantado, la escasa capacidad adquisitiva y, consiguientemente, contributiva de la mayoría de la población. Las actas municipales de Izalco permiten comprobar algunos de los asuntos de importancia que se trataban en la alcaldía y, como sucede con los fondos documentales de otras instituciones de la localidad, un análisis en mayor extensión permitirá estudiar en detalle las cuestiones más relevantes que vivía la ciudad. Los ejemplos que se exponen a continuación corresponden a un momento previo a los efectos de la crisis de 1929 para observar el funcionamiento de la alcaldía en momentos de relativa normalidad.

Así, en junio de 1927 la municipalidad aprobó dirigirse al presidente de la República Pío Romero para que concediera los 4.000 colones que había prometido para la obra de la cárcel de mujeres, nuevas oficinas municipales, la presa que surtía de agua potable a la ciudad y un nuevo edificio escolar. ${ }^{49}$ Este era el tipo de subvenciones extraordinarias que los municipios solicitaban dada su ha-

48. Alcalde de Tacuba al gobernador de Ahuachapán y de este al ministro de Gobernación, en AGN, Gob, Ahuachapán, 1929/51-4, 9 de noviembre de 1929. La referencia a 1911 en Planilla de gastos de albañiles y mozos en obra de cloaca de Sonsonate, en AGN, Gob Son, 11.

49. Acta de sesión municipal de 4 de junio de 1927 en AMI. 
bitual falta de recursos. En este caso, la promesa parece que partió del presidente, aunque la aprobación de los fondos correspondía a la Asamblea. No se puede descartar que, en este caso, como sucedía en otros de distintos municipios, la intención de ayudar por parte de las altas autoridades de la República no pudiera concretarse porque la Hacienda nacional tampoco disponía de recursos. En efecto, en enero de 1928 los fondos prometidos no habían llegado, las obras estaban sin concluir y el déficit dejado por el equipo municipal saliente a finales de 1927 impedía disponer de recursos. ${ }^{50}$

Una obligación anual eran las obras de mantenimiento de las vías que comunicaban la veintena de cantones del municipio. Después de la estación de lluvias era preciso acondicionar las varias decenas de kilómetros de los caminos vecinales. En septiembre de 1927 la alcaldía tenía reservados para ello 180,72 colones, que era una cifra manifiestamente insuficiente. Por ello se pidió autorización a la Gobernación Departamental para poder emplear la recaudación del Fondo de Caminos en aquellos trabajos. ${ }^{51}$ Paradójicamente, pese a la denominación de este impuesto, su destino no era la composición de caminos, sino que era un impuesto estatal recaudado por los municipios; sin embargo, los recursos bajo esta titulación debían ser enviados a la Administración de Rentas de los Departamentos. Por eso, para poder utilizarlos con otra finalidad era preciso solicitar permiso al gobernador del Departamento. En todo caso, es altamente probable que no hubiera fondos suficientes para pagar jornales, ni para comprar herramientas y materiales, por lo que no todos los caminos quedarían en buenas condiciones para soportar el tránsito durante meses.

Como sucedía en estos años en gran parte de la República, se estaba generando una protesta popular muy extendida en un amplio número de municipios debido al alto precio de la energía eléctrica. El servicio era, sobre todo, para el alumbrado público, porque eran pocos ciudadanos los que se podían permitir alumbrado eléctrico en sus viviendas. ${ }^{22}$ Este asunto ya había dado lugar a quejas puntuales años atrás en algunos pueblos donde se llegó a solicitar la anulación del contrato de la luz eléctrica por la dificultad que tenían muchos vecinos para pagar su cuota. Las empresas más fuertes, como la Compañía de la Luz Eléctrica de San Salvador o la de Santa Ana, habían sido creadas por capitales de origen en el café y, además de las ciudades, abastecían a localidades menores.

El mismo caso era el de la Compañía Eléctrica de Sonsonate, que trabajaba en la capital de este Departamento pero también surtía a Izalco, entre otros pueblos. Con la difusión de la generación de electricidad gracias a los muchos cursos de agua que había en el país, se fueron creando otras compañías menores, a veces por parte de ricos propietarios que generaban su propia energía para los motores de beneficio de café en sus fincas. Esto había sucedido en 1927 en Juayúa, localidad próxima a Izalco. Allí un tal Leandro Mata había ope-

50. Acta de sesión municipal de 5 de enero de 1928 en AMI.

51. Acta de sesión de 24 de septiembre de 1927 en AMI.

52. AGN, MGob, 1930/52-4. 
rado de esta forma y, como tenía un exceso de capacidad de producción eléctrica, ofreció a la municipalidad de Izalco contratar la energía eléctrica con él. Pero el contrato firmado con la empresa de Sonsonate en 1915 incluía una cláusula que prohibía contratar con otro proveedor mientras aquella estuviera en funcionamiento. ${ }^{53}$ En aquellos momentos la municipalidad estaba endeudada con la compañía eléctrica de Sonsonate y le estaba pagando la deuda en cuotas. ${ }^{54}$

Mata insistió al municipio protestando por el injusto monopolio de la empresa de Sonsonate. Señalaba que los caminos eran nacionales y que él tenía derecho a colocar los postes necesarios para llevar a Izalco la energía, la cual, además, la cobraría el $20 \%$ más barata que el precio que la municipalidad estaba pagando entonces. El Ayuntamiento se mostró de acuerdo y decidió enviar la solicitud del cambio al Gobierno. ${ }^{55}$ Sin embargo, la compañía de Sonsonate se dirigió de nuevo a la municipalidad, esta vez a través del gobernador, en octubre de 1928, exigiéndole el pago de ocho meses de alumbrado que le debía y que ascendían a 2.292 colones. Pero la municipalidad estaba imposibilitada para cumplir con el pago, debido a la cantidad de ciudadanos morosos a los que no era capaz de hacerles pagar. Ya en febrero de 1928 la alcaldía decidió crear una comisión presidida por el síndico municipal para llevar a los morosos ante los tribunales de justicia y ejecutar las deudas que tenían con la municipalidad. Ahora, en octubre, tras la presión de la compañía de electricidad y dada la tensión producida, el municipio decidió dar orden a la policía de arrestar a los ciudadanos morosos para intentar que pagaran dos mensualidades cada mes. ${ }^{56}$ Pero el problema de Izalco con la energía eléctrica no era aislado, sino que se enmarcaba en un movimiento mucho más amplio.

El municipio sufría la "exhaustez" ${ }^{57}$ habitual de recursos y no podía pagar los salarios de sus trabajadores normalmente. Así, los empleados municipales pedían trabajar solo de siete a doce de la mañana, lo que en principio les fue concedido, pero posteriormente regresaron a su horario de mañana y tarde. Por su parte, a los secretarios de los juzgados Primero y Segundo de Paz se les redujo el sueldo mensual de 30 a 20 colones. Ante esta medida, uno de los secretarios dimitió y en octubre se les restituyeron los salarios de 30 colones a los secretarios de juzgados, como estaba previsto en el presupuesto municipal..$^{58}$

En suma, estos breves ejemplos sirven para mostrar cómo la vida municipal reflejaba el panorama social del país con sus desigualdades y problemas.

53. Acta de sesión municipal de 15 de junio de 1927, en AMI.

54. Acta de sesión municipal de 24 de septiembre de 1927, en AMI.

55. Acta de sesión municipal de 15 de noviembre de 1927, en AMI.

56. Acta de sesión municipal de 5 de octubre de 1928, en AMI.

57. Era el término utilizado normalmente en la Hacienda nacional y en las locales para referirse a la extrema escasez de fondos.

58. Actas de sesiones municipales del 5 de septiembre y el 5 de octubre de 1927, en AMI. 


\section{Conclusiones}

En aquel estado de cosas, en Izalco, que solo era una parte, aunque muy singular, del contexto del país, la crisis de 1929 trajo las consecuencias que son conocidas: entre otras, la caída de los precios de las exportaciones y del comercio internacional, especialmente hacia los Estados Unidos. El desplome de las rentas públicas y privadas generó tensiones en el ámbito de la producción, en la sociedad en su conjunto y en la gestión política, que ya había comenzado una fuerte crisis en 1928. Amplios sectores de las minorías propietarias se radicalizaron frente a las crecientes demandas del mundo trabajador. El nuevo presidente, Arturo Araujo, que había comenzado a gobernar en 1931 en un país fuertemente polarizado y con un vicepresidente militar, no pudo soportar las fuertes tensiones sociales y políticas. En diciembre de 1931 el vicepresidente, el general Maximiliano Hernández Martínez, dio un golpe de Estado con el que dio inicio a una dictadura. Y en enero de 1932 tuvo lugar la matanza de miles de trabajadores, en cantidad indeterminada, que fue una de las mayores tragedias de América Latina en la primera mitad del siglo xx. Fue el culmen de la radicalización de la oligarquía de El Salvador.

\section{Bibliografía}

AcostA, Antonio (2013). Los orígenes de la burguesía de El Salvador. El control sobre el café y el Estado, 1848-1890. Barcelona-Sevilla: TEIAA / IEAL.

Acosta, Antonio y FloRES, Julia (2011). «Municipio y Estado: política municipal de los gobiernos de El Salvador hacia 1900». En: LóPEZ BeRnAL, Carlos Gregorio (comp.). Poder, actores sociales y conflictividad. El Salvador (1786-1972). San Salvador: Dirección Nacional de Investigaciones en Cultura y Arte, SECULTURA, págs. 168-208.

Alvarenga Venutolo, Patricia (2006). Cultura y ética de la violencia. El Salvador 18801932. San Salvador: CONCULTURA.

ANDERSON, Thomas (1971). Matanza. The communist revolt of 1932. Lincoln: University of Nebraska Press.

Anuario Estadístico (1924). Anuario Estadístico de El Salvador. San Salvador: s/e

Ching, Erik C., López Bernal, Carlos Gregorio y Tilley, Virginia K. (2007). Las masas, la matanza y el martinato: ensayos sobre 1932. San Salvador: UCA Editores.

ClaRÁ De Guevara, Concepción (1975). Exploración etnográfica: Departamento de Sonsonate. San Salvador: Ministerio de Educación.

CLARENCE-Smith, William Gervase y ToPIK, Steven (2003). The global coffee economy in Africa, Asia, and Latin America. 1500-1989. Cambridge / Nueva York: Cambridge University Press.

GIUDICELLI, Christophe (2005). «El miedo a los monstruos. Indios ladinos y mestizos en la guerra de los Tepehuanes de 1616». Nuevo Mundo Mundos Nuevos, París, Bibliothèque des Auteurs du Centre. Disponible en: http://journals.openedition.org/nuevomundo/614.

Gould, Jeffrey y LAURIA-SANTIAGo, Aldo (2008). To rise in darkness. Revolution, repression and memory in El Salvador, 1920-1932. Durham/Londres: Duke University Press. 
LauriA-SANTIAgo, Aldo (1995). «Los indígenas de Cojutepeque. La política faccional y el Estado nacional en El Salvador, 1830-1890». En: TARACENA, Arturo y PIEL, Jean (comps.). Identidades nacionales y Estado moderno en Centroamérica. San José: Editorial de la Universidad de Costa Rica, págs. 237-252.

LaURIA-SANTIAgo, Aldo (1998) «Historia regional del café en El Salvador». Revista de Historia, San José, Universidad Nacional de Costa Rica, 38, págs. 9-61.

LAURIA-SANTIAGo, Aldo (1999). «Land, community and revolt in late-nineteenth-century Indian Izalco, El Salvador». The Hispanic American Historical Review, Durham, 79 (3), págs. 495-534.

LeIVA Masin, Julio (2011). Los Izalcos. Testimonio de un indígena. San Salvador: Editorial Universitaria, Universidad de El Salvador.

LÓPEZ BeRnAL, Carlos Gregorio (2000). «El levantamiento indígena de 1846 en Santiago Nonualco. Conflictos locales, etnicidad y lucha de facciones en El Salvador». Revista de Historia, San José, 42, págs. 9-43.

LÓPEZ BernaL, Carlos Gregori (2008). «El levantamiento de los indios nonualcos en 1832. Hacia una nueva interpretación». Hacer Historia en El Salvador. Revista Electrónica de Estudio Históricos, Toulouse, 1/1, págs. 23-29.

MARICHAL, Carlos (1989). A century of debt crisis in Latin America. From Independence to the Great Depression. Princeton: Princeton University Press.

MARTínEZ, Néstor (2012). «Los orígenes de la matanza indígena de 1932 en El Salvador». Diario CoLatino, San Salvador, 3 de noviembre.

Menuívar, Rafael (1979). Formación y lucha del proletariado industrial salvadoreño. San José: Editorial Universitaria Centroamericana.

MENJívar, Rafael (1980). Acumulación originaria y desarrollo del capitalismo en El Salvador. San José: Editorial Universitaria Centroamericana.

RIVAS, Ramón (2002). «Persistencia indígena en El Salvador». Científica, San Salvador, 5, págs. 29-49.

RodríGuez-Herrera, América (2007). «Agua e identidad étnica en Izalco, República de El Salvador». Agricultura, Sociedad y Desarrollo, Texcoco, 4 (2), págs. 83-103.

SMiтH, Robert S. (1963). «Financing the Central American Federation, 1821-1838». The Hispanic American Historical Review, Durham, 43 (4), págs. 483-510.

Fecha de recepción: 3 de junio de 2021

Fecha de aceptación: 9 de septiembre de 2021

Fecha de publicación: 22 de diciembre de 2021 